$1988,37,1$

УдК 577.153 .4

Реэт ТООМИК, Марика ЭЛЛЕР, Я. ЯРВ

\title{
ВЗАИМОДЕЙСТВИЕ ХОЛИНЭСТЕРАЗ С АФФИННЫМИ СОРБЕНТАМИ НА БАЗЕ ПРОИЗВОДНЫХ ФЕНИЛЕНДИАМИНОВ
}

\author{
(Представил О. Ұйзен)
}

Эффективное взаимодействие катионных лигандов с холинэстеразами открывает возможность очистки этих ферментов методом аффинной хроматографии $\left[{ }^{1-8}\right]$. Необходимые для этой цели аффинные сорбенты получают иммобилизацией на полимерных носителях органических веществ, содержащих в своей структуре аммониевые или аминогруппы. Как правило, эти соединения также способны обратимо ингибировать катализируемый холинэстеразами гидролиз субстратов и эффективность их связывания с ферментами определяется ингибиторной константой $K_{i}$. На основании этих параметров можно анализировать закономерности влияния строения лигандов на их связывающие свойства в растворе. При связывании лиганда с матрицей аффинного сорбента эффективность связывания фермента с лигандом может определяться, кроме строения лиганда, и другими факторами []. Такими факторами могут быть, например, длина и химическая природа «ножки», пришивающей лиганд к носителю, а также свойства микроокружения лиганда в полимерной структуре матрицы сорбента. Для оценки роли последних факторов в системах, представляющих интерес с точки зрения аффинной хроматографии холинэстераз, в настоящей работе исследовали закономерности взаимодействия ацетилхолинэстеразы яда кобры и бутирилхолинэстеразы сыворотки крови лошади с серией аффинных сорбентов, полученных из мета- и парапроизводных фенилендиаминов:

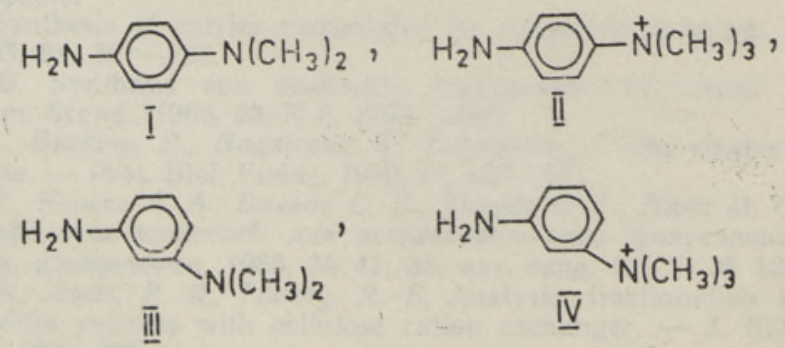

В качестве носителей использовали агарозные гели со следующими структурами «ножки»:

$$
\begin{array}{cl}
\mathrm{V} & -\mathrm{NH}-\left(\mathrm{CH}_{2}\right)_{6}-\mathrm{COOH}, \\
\mathrm{VI} & -\mathrm{NH}-\left(\mathrm{CH}_{2}\right)_{6}-\mathrm{NHCO}-\mathrm{CH}_{2}-\mathrm{CH}_{2}-\mathrm{COOH}, \\
\mathrm{VII} & -\mathrm{O}-\mathrm{CH}_{2}-\mathrm{CH}-\mathrm{CH}_{2}-\mathrm{O}-\left(\mathrm{CH}_{2}\right)_{4}-\mathrm{O}-\mathrm{CH}_{2}-\mathrm{CH}-\mathrm{CH}_{2} .
\end{array}
$$


Сорбенты типа V и VI - производные CH- и АН-агарозы. В последнем случае «ножку» удлиняли присоединением сукцинангидрида. Связывание лиганда проводили в обоих случаях с помощью водорастворимого карбодиимида. Сорбент типа VII был получен на базе эпокси-активированной агарозы. Присоединение лигандов I-IV к последнему типу носителя можно проводить без карбодиимида. В результате синтезов были получены аффинные сорбенты с содержанием лигандов в интервале от 2,1 до 2,4 мM в случае носителей V и VI и от 1,3 до 1,8 мM в случае носителя VII.

Связывание холинэстераз с полученными сорбентами исследовали в равновесных условиях, измеряя уменьшение концентрации свободного фермента при добавлении к раствору малых порций геля. Проведение опытов при разных исходных концентрациях фермента допускало определение изотермы равновесного связывания холинэстераз с аффинными сорбентами (рис. 1). Отдельно исследовали неспецифическое связывание обоих ферментов с гелями, содержащими только «ножку», без лиганда. Этот анализ показал, что в случае структур V и VI эффект неспецифического связывания обоих типов холинэстераз с носителем не превышает одного процента от специфического связывания в условиях насыщения геля ферментом. Поэтому в последующих опытах эффектом неспецифического связывания пренебрегали. Однако для носителя VII связывание ферментов с сорбентом без аффинных лигандов достигает $95 \%$ от общег связывания. Поэтому соответствующая структура сорбента была признана неперспективной для аффинной хроматографии холинэстераз и

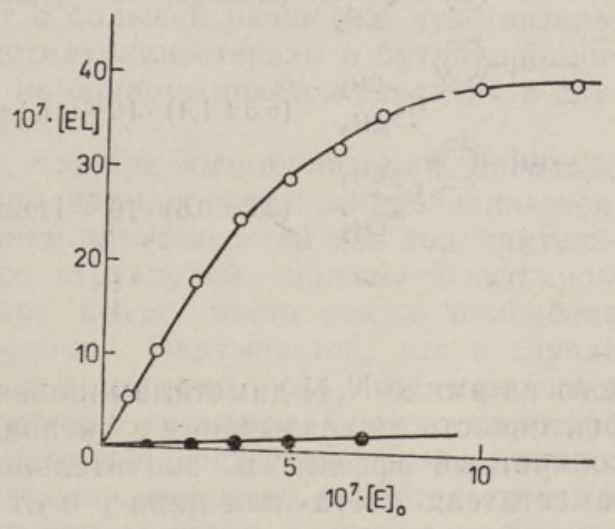

Рис. 1. Изотерма связывания бутирилхолинэстеразы с аффинным сорбентом, синтезированным из СН-arapoзы и лиганда IV (О). Неспецифическое связывание этого фермента с гелем без лиганда (). Условия опыта: 0,05 M K-фосфатный буфер, pH 7,50, $25^{\circ} \mathrm{C}$. дальнейшие опыты проводили только с сорбентами на базе агароз типа $\mathrm{CH}$ и $\mathrm{AH}$ (V и VI).

Данные равновесного связывания ферментов с аффинными сорбентами анализировали исходя из равновесной схемы связывания

$$
E+L \stackrel{K_{L}}{\rightleftharpoons} E L
$$

для которой в $\left[{ }^{10}\right]$ выведено выражение для расчета константы $K_{L}$ по данным связывания фермента с маленькими порциями геля:

$$
K_{L}=\left(\frac{[E]_{0}}{[E L]} \cdot V-v\right) \cdot \frac{[L]_{0}}{V+v} .
$$

В этом уравнении $[E]_{0}$ - начальная концентрация фермента в фазе раствора, $[E L]$ - равновесная концентрация комплекса фермент-лиганд в аффинном сорбенте, $V$ - начальный объем раствора фермента, $v$-. объем фазы геля, $[L]_{0}$ - начальная концентрация лиганда в геле. Полученные по уравнению (2) значения $K_{L}$ приведены в табл. 1.

Для сравнения определяли с обоими ферментами также ингибиторные константы $K_{i}$ для ацетилированных лигандов I-IV. Для этой цели использовали данные ингибирования катализируемого холинэстеразами гидролиза ацетилхолина. Результаты этих опытов (табл. 2) показали, что образование четвертичного триалкилфениламмониевого производ- 
Взаимодействие ацетилхолинэстеразы и бутирилхолинэстеразы с аффинными сорбентами. Условия: 0,05 М К-фосфатный буфер, pH 7,50, $25^{\circ} \mathrm{C}$

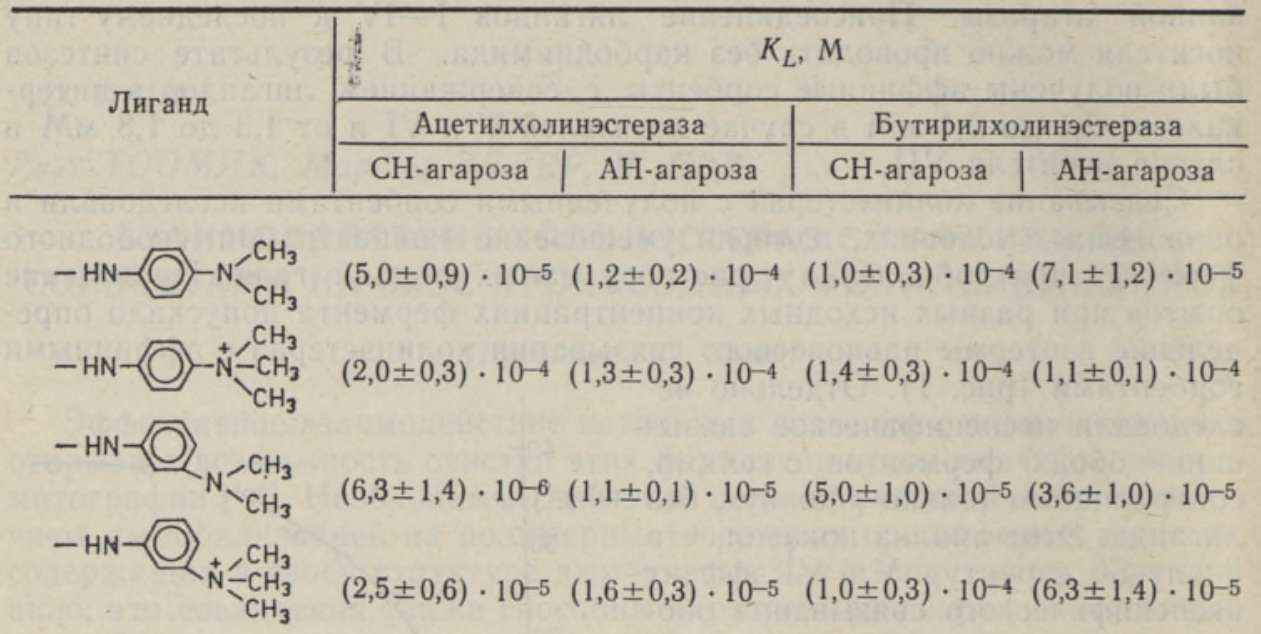

ного из амино-N, N-диметиламинобензена значительно увеличивает эффективность их связывания в активных центрах холинэстераз. При этом конкретный эффект в значительной степени зависит от положения заместителя (мета- или пара-) и от типа фермента. Наиболее чувствительной является ацетилхолинэстераза относительно алкилирования заместителя в мета-положении. Остро выраженная селективность этого фермента относительно триметиламмониевой группы в мета-положении фенильного заместителя $[11,12]$, очевидно, связана с некоторыми структурными особенностями активной поверхности ацетилхолинэстеразы.

Таблица 2

Взаимодействие ацетилхолинэстеразы и бутирилхолинэстеразы с ацетилированными лигандами. Условия: $0,15 \mathrm{M} \mathrm{KCl,} \mathrm{pH} 7,50,25^{\circ} \mathrm{C}$

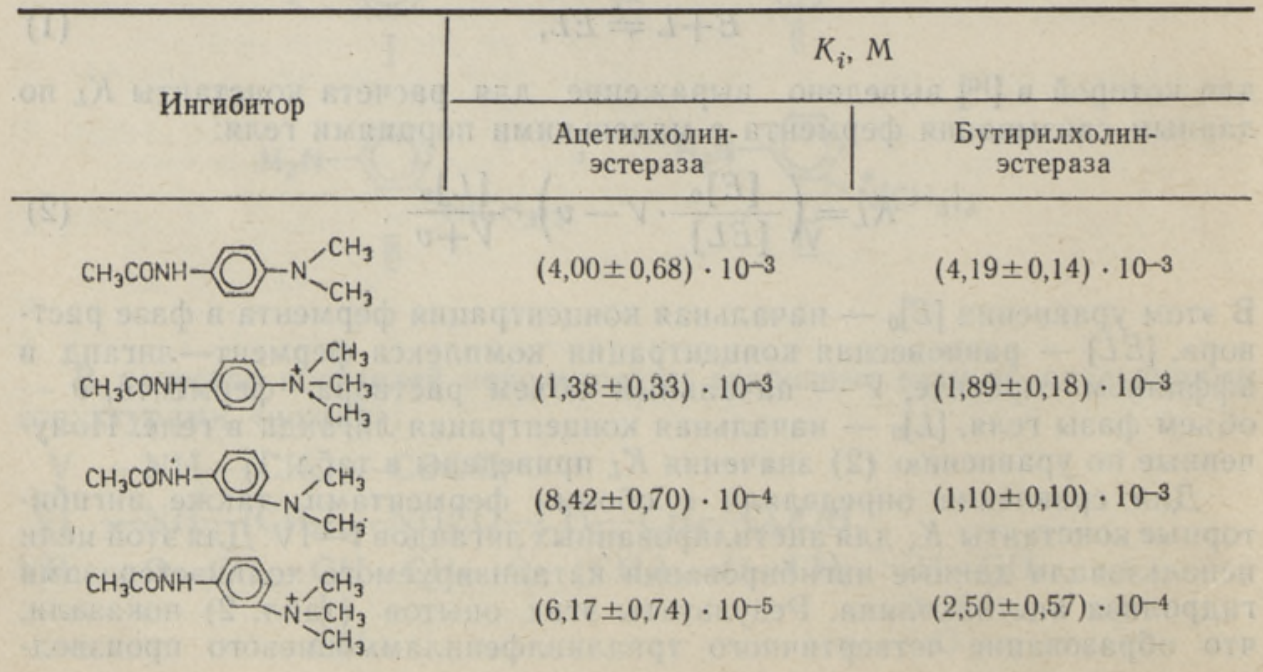


Несмотря на разные эффекты варьирования строения ингибиторов, оба фермента обладают в общем одинаковой специфичностью относительно изученных лигандов. Об этом свидетельствует соблюдение хорошей линейной зависимости между величинами $p K_{i}$ для ацетилхолинэстеразы и бутирилхолинэстеразы (рис. 2). Из этой линейной зависимости получим по уравнению

$$
p K_{i}^{\mathrm{LX} \ni}=\alpha p K_{i}^{\mathrm{AX} \ni}+\mathrm{const}
$$

$\alpha=0,66 \pm 0,05$ и const $=0,83 \pm 0,15$. Значение $\alpha<1$ показывает, что ацетилхолинэстераза и бутирилхолинэстераза обладают неодинаковой чувствительностью относительно структуры лигандов.

Из аналогичных данных для иммобилизованных лигандов (рис. 3) видно, что и в этом случае соблюдается соотношение (3), но величина $\alpha=0,28 \pm 0,09$ еще ниже, что говорит о большей разнице в чувствительностях к эффектам строения для ацетилхолинэстеразы и бутирилхолинэстеразы. При этом характерно, что не обнаруживается различий в случае АН- и СН-производных агарозы.

Полученные данные показывают, что при иммобилизации лигандов эффективность их связывания с ферментами несколько увеличивается. Вероятно, что это связано с появлением возможностей для дополнительных гидрофобных взаимодействий со структурой «ножки» в активном центре фермента. При этом, однако, имеет место также изменение последовательности эффектов строения. Оказывается, что в случае аффинных сорбентов метилирование диметиламиногруппы уменьшает эффективность взаимодействия фермента с лигандом. Соответствующие эффекты весьма значительны для ацетилхолинэстеразы. Такое изменение последовательности эффектов строения, очевидно, свидетельствует о разной локализации этих групп в активном центре в случае растворимого и иммобилизованного лигандов.

Из полученных результатов также видно, что бутирилхолинэстераза в значительной степени теряет способность «узнавать» строение лигандов, полученных на базе фенилендиаминов, что важно учитывать при конструировании эффективного аффинного сорбента для этого фермента.

Таким образом, полученные данные показывают, что при иммобилизации производных фенилендиаминов значительно меняется зависимость эффективности их связывания с ферментом от строения реагентов. Следовательно, наблюдаемые для ингибиторных констант $K_{i}$ закономерности

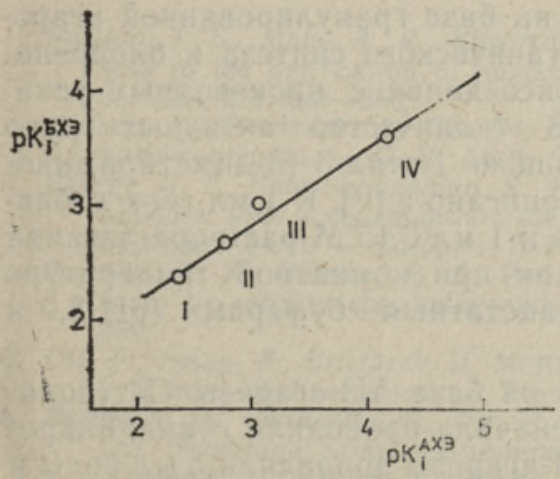

Рис. 2. Сопоставление ингибиторных свойств $\mathrm{N}$-ащетилированных аммониевых лигандов для ацетилхолинэстеразы и бутирилхолинэстеразы. Номера точек соответствуют структурам лигандов I-IV.

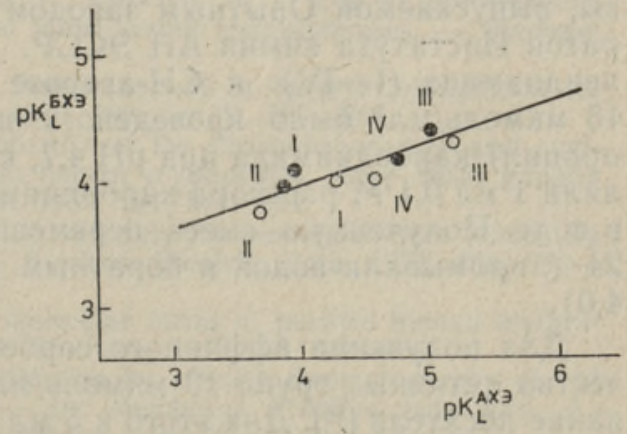

Рнс. 3. Сопоставление эффективности связывания ацетилхолинэстеразы и бутирилхолинэстеразы с аффинными сорбентами на базе $\mathrm{AH}$-агарозы (2) и $\mathrm{CH}$ агарозы (О). Номера точек соответствуют структурам лигандов I-IV. 
не могут бытъ использованы в качестве «модельной системы» при создании аффинных сорбентов для ферментов класса холинэстераз. При этом не соблюдается также общепризнанный принцип увеличения эффективности связывания с холинэстеразой лиганда при кватернизации в его структуре атома азота. Этими изменениями в специфичности ферментлигандного взаимодействия, очевидно, и объясняются трудности при попытках создания эффективных аффинных сорбентов для бутирилхолинэстеразы. С другой стороны, однако, «инверсия» специфичности при иммобилизации лигандов с амино- и аммониевыми группами открывает перспективу целенаправленного создания более эффективных по сравнению с существующими системами аффинных сорбентов для ацетилхолинэстеразы.

\section{Экспериментальная часть}

В качестве источника ацетилхолинэстеразы использовали яд среднеазиатской кобры (Naja паја охіап). Препарат VI класса бутирилхолинэстеразы сыворотки крови лошади был получен в Московском НИИ вакцин и сывороток им. И. И. Мечникова. Концентрацию фермента в обонх препаратах определяли по скорости гидролиза ацетилтиохолина в оптимальных условиях реакции [13].

Гидрохлорид 3-амино-N, N-диметиламинобензена был синтезирован по методике $\left.{ }^{14}\right]$ из $\mathrm{N}, \mathrm{N}$-диметиланилина (Реахим). Данные элементного анализа соответствующего $\mathrm{N}$-ацетилированного производного, \%; С 66,49; Н 7,54, N 15,79; вычислено, \%: С 67,37, Н 7,92, N 15,72. 4-Амино-N, N-диметиламинобензен использовали в виде сульфата (Реахим).

Оба продукта ацетилировали уксусным ангидридом и алкилировали иодистым метилом в среде ацетона [14]. Полученные триметиламмониевые соли деацетилировали $50 \%$-ным раствором $\mathrm{HCl}$ в этаноле и перекристаллизовывали из смеси этанола и этилацетата в виде соответствующих хлоридов. Данные элементного анализа, \%: С 48,08, Н 7,24, N 12,25 для хлористого 3-амино-N, N, N-триметилфениламмония и С 48,40, Н 7,20, N 11,91 для хлористого 4-амино-N, N, N-триметилфениламмония. Вычислено, \%: C 48,44, Н 7,23, N 12,55. Чистота всех конечных продуктов синтеза была проверена методом тонкослойной хроматографии на пластинках Силуфол, элюент бутанол-уксусная кислота-вода $(4: 1: 1)$, проявление парами $\mathrm{I}_{2}$.

Аффинные сорбенты синтезировали на базе гранулированной агарозы, выпускаемой Опытным заводом органического синтеза и биопрепаратов Института химии АН ЭССР. Присоединение производных фенилендиамина (I-IV) к CH-агарозе 4B (количество активных групп 15 мкмоль/мл) было проведено с помощью 1-этил-3-(3-диметиламинопропил) -карбодиимида при $\mathrm{pH} 4,7$, как описано в [ $\left.{ }^{15}\right]$. K 1 мл геля добавляли 1 мл 0,1 M раствора карбодиимида и 1 мл 0,15 M раствора лиганда в воде. Полученную смесь перемешивали при комнатной температуре 24 ч, промывали водой и боратным и ацетатным буферами (рН 8,0 и $4,0)$.

Для получения аффинного сорбента на базе АН-агарозы 4B (количество активных групп 18 мкмоль/мл) сначала проводили сукцинилирование носителя $\left[{ }^{16}\right]$. Для этого к 5 мл АН-агарозы добавляли 5 мл воды и 0,5 г сукцинангидрида, смесь поддерживали, осторожно перемешивая, при рН 6 (рН-стат фирмы «Radiometer», Дания; комплект PHМ 82, TTT 80, ABU 80). Реакцию проводили при $4{ }^{\circ} \mathrm{C}$ в течение 5 ч. Получасмый гель промывали $1 \mathrm{M} \mathrm{NaCl}$ и водой. Производные фенилендиамина присоединяли к этому носителю карбодиимидным методом, как описано выше в случае СН-агарозы. 
Эпокси-активированное производное агарозы (VII) получали из неактивированной агарозы $6 \mathrm{~B}$ и 1,4-бис (2,3-эпоксипропокси)-бутана $\left[{ }^{17}\right]$. Концентрацию активных групп определяли титрованием геля $0,1 \mathrm{M} \mathrm{HCl}$ в присутствии тиосульфата натрия [ $\left.{ }^{17}\right]$. Разные синтезы дали содержание эпоксигрупп в геле от 25 до 30 мкмоль/мл геля. Присоединение к этому носителю производных фенилендиамина проводили, как описано в [15], добавляя к активированному гелю 10-кратный избыток лиганда и $\mathrm{pH}$ раствора доводили до 9,5. Полученную смесь тщательно перемешивали при $45^{\circ} \mathrm{C}$ в течение 48 ч, промывали водой и боратным (pH 8,0) и ацетатным (рН 4,0) буферами.

Концентрацию связанного с гелем лиганда определяли спектрофотометрическим методом [9]. УФ-спектры сорбентов снимали на спектрофотометре «Perkin Elmer 420», используя суспензию геля в этиленгликоле (1:10 по объему).

Связывание холинэстераз с аффинными сорбентами определяли по уменьшению активности фермента в пробах после добавления туда образца геля. Объем пробы 0,32 мл, объем добавляемого геля 0,03 мл. Суспензию геля в растворе фермента инкубировали в течение 4 ч $\left(25^{\circ} \mathrm{C}\right)$, затем сорбент осаждали центрифугированием 3000 об/мин в течение 5 мин. Из супернатанта отбирали пробы, в которых измеряли активность холинэстераз спектрофотометрическим методом $\left[{ }^{13}\right]$, используя ацетилтиохолин в качестве субстрата. Данные анализировали в координатах изотермы связывания фермента с сорбентом по зависимости концентрации связанного с гелем фермента от концентрации фермента в пробе (см. рис. 1).

Константы диссоциации комплекса фермента с иммобилизованным лигандом $K_{L}$ рассчитывали по формуле (2). При этом использовали данные не менее 5 опытов, что допускало расчет среднего значения $K_{L}$ и его среднеквадратичной погрешности. При этом по линейной зависимости $[E L]$ от $[E]_{0}$ проверяли соблюдение условий, где порция геля не была насыщена ферментом (рис. 1).

Көнстанты $K_{i}$ определяли в бимолекулярных условиях субстратной реакции $\left[{ }^{18}\right]$. Опыты проводили в условиях рН-статического титрования в $0,15 \mathrm{M} \mathrm{KCl}, \mathrm{pH} 7,50,25^{\circ} \mathrm{C}$, используя ацетилхолиниодид («Reanal», BHP) в качестве субстрата для обоих типов холинэстераз.

\section{Л И ТЕ РА Т У Р А}

1. Ralston, J. S., Main, A. R., Kilpatrick, B. F., Chasson, A. L. Use of procainamide gels in the purification of human and horse serum cholinesterases, - Biochem. J., 1983, 211, 243-250.

2. Masson, P., Sussmilch, A., Charlet, J.-P. Purification de la butyrylcholinestẹ́rase du plasma humain. - C. R. Acad. Sci., 1980, 290, ser. D, 857-860.

3. George, S. T., Balasubramanian, S. The identity of the serotonin-sensitive aryl acylamidase with acetylcholinesterase from human erythrocytes, sheep basal ganglia and electric eel. - Europ. J. Biochem., 1980, 111, 511-524.

4. Tripathi, R. K., O'Brien, R. D. Purification of acetylcholinesterase from house fly brain by affinity chromatography. - Biochim. Biophys. Acta, 1977, 480, 382389.

5. Ott, P., Jenny, B., Brodbeck, U. Multiple molecular forms of purified human erythrocyte acetylcholinesterase. - Europ. J. Biochem., 1975, 57, 469-480.

6. Brodbeck, U., Gentinetta, R., Ott, P. Purification by affinity chromatography of red cell membrane acetylcholinesterase. - In: Membrane Proteins (eds Azzi, A., Brodbeck, U., Zahler, P.). Berlin-Heidelberg-New York, 1981, 84-96.

7. Dawson, R. M., Crone, H. D. Affinity chromatography of Triton-solubilized brain acetylcholinesterase. - J. Chromatogr., 1974, 92, 349-354.

8. Chan, S. L., Shirachi, D. Y., Bhargava, H. N., Gardner, E., Trevor, A. J. Purification and properties of multiple forms of brain acetylcholinesterase (EC 3.1,1.7). J. Neurochem., 1972, 19, 2747-2758.

9. Туркова Я. Аффннная хроматография. М., 1980, 62-103. 
10. Graves, $D . J_{.}, W u, Y .-T$. On predicting the results of affinity procedures. - In: Mehods in Enzymol., 34, Pt B. New York et al., 1974, 140-163.

11. Metcalf, $R$. L., Fukuto, $T$. R. Effects of chemical structure on intoxication and detoxication of phenyl $\mathrm{N}$-methylcarbamates in insects. - J. Agric. Food Chem., $1965,13, \mathrm{~N} \mathrm{3}, 220-230$.

12. Nishioka, T., Fujita, T., Kamoshita, K., Nakajima, M. Mechanism of inhibition reaction of acetylcholinesterase by phenyl N-methylcarbamates. - Pestic. Biochem. Physiol., 1977, 7, 107-121.

13. Ellmann, G. L., Courtney, K. D., Andres, V. Jr., Featherstone, R. M. A new and rapid colorimetric determination of acetylcholinesterase activity. - Biochem. Pharmacol., 1961, 7, 88-95.

14. Traylor, $P$. S., Singer, S. J. Preparation and properties of some tritiated diazonium salts and related compounds. - Biochemistry, 1967, 6, N 3, 881-887.

15. Practical Guide for Use in Affinity Chromatography and Related Techniques. Réactifs IBF-Société Chimique Pointet-Girard, 1983, 134, 126.

16. Cuatrecasas, $P$. Protein purification by affinity chromatography. Derivatizations of agarose and polyacrylamide beads. - J. Biol. Chem., 1970, 245, N 12, 30593065 .

17. Sundberg, L., Porath, J. Preparation of adsorbents for biospecific affinity chromatography. I. Attachment of group-containing ligands to insoluble polymers by means of bifunctional oxiranes, - J. Chromatogr., 1974, 90, 87-98.

18. Силлард Р. Г., Ярв Я. Л. Тройные комплексы и исследование обратимых ингибиторов бутирилхолинэстеразы. - В кн.: III Всесоюзная межуниверситетская конференция по физико-химической биологин, II. Тбилиси, 1982, 434-435. Тартуский государственный
университет

\section{Поступила в редакцию 20/IV 1987}

\section{Reet TOOMIK, Marika ELLER, J. JARRV \\ KOLIINESTERAASIDE SEOSTUMINE FENULEENDIAMIINIDE BAASIL SUNTEESITUD AFIINSUSSORBENTIDEGA}

Lähtudes fenüleendiamiini derivaatidest on sünteesitud $\mathrm{CH}$-, $\mathrm{AH}$ - ja epoksüagaroosi baasil 12 erinevat afiinsussorbenti. On määratud vastavate seostumisreaktsioonide dissotsiatsioonikonstandid $K_{L}$ atsetüülkoliinesteraasi ja butürüülkoliinesteraasi jaoks tasakaalutingimustel $\left(0,05 \mathrm{M} \mathrm{K}\right.$-fosfaatpuhver, $\left.\mathrm{pH} 7,50,25^{\circ} \mathrm{C}\right)$. Tulemusi on vorrreldud atsetüültiokoliini hüdrolüüsireaktsioonil vastavate atsetüülaniliidide jaoks määratud inhibeerimiskonstantidega $K_{i}$. On näidatud atsetüülkoliinesteraasi ja butürüülkoliinesteraasi ühesugust spetsiifilisust fenüleendiamiinide suhtes, kusjuures pärast immobiliseerimist inhibeerivate omaduste pōhjal reastatud ligandide järjestus muutus. Kõige efektiivsemaks afiinsussorbendiks osutus $\mathrm{m}-\mathrm{N}, \mathrm{N}$-dimetüülfenüleendiamiin, aktiivseim vaba ligand oli aga vastav $\mathrm{N}, \mathrm{N}, \mathrm{N}$-trimetüülammooniumderivaat.

\section{Reet TOOMIK, Marika ELLER, J. JÄRV}

\section{INTERACTION OF CHOLINESTERASES WITH AFFINITY SORBENTS ON THE BASIS OF PHENYLENDIAMINE DERIVATIVES}

Proceeding from $\mathrm{CH}-\mathrm{AH}$ - and epoxy-agarose, 12 different affinity sorbents were synthesized by making use of phenylendiamine derivatives as affinity ligands. Binding of acetylcholinesterase and butyrylcholinesterase with these sorbents has been studied under the equilibrium conditions. The appropriate dissociation constants $K_{L}$ were determined $\left(0.05 \mathrm{M}\right.$ K-phosphate buffer, $\left.\mathrm{pH} 7.50,25^{\circ} \mathrm{C}\right)$. The results were compared with the inhibitory constants $K_{i}$ for the appropriate acetylanilides, obtained from the inhibition by these compounds of cholinesterase-catalyzed hydrolysis of acetylthiocholine. It has been shown that both cholinesterases reveal similar specificity against the phenylendiamine derivatives. The consequence of the inhibitory effects, however, depends upon the state of ligand and remarkably changes due to immobilization of the ammonium compound in gel structure. In the sorbent-bound state the most effective binding of cholinesterases can be observed in the case of meta-derivatives of N,N-dimethylphenylendiamine, while in solution the most potent compound was the appropriate $\mathrm{N}, \mathrm{N}, \mathrm{N}$-trimethylammonium derivative. 